\title{
GCU
}

Glasgow Caledonian

University

University for the Common Good

\section{Size effect on fracture properties of concrete after sustained loading}

Rong, Hua; Dong, Wei; Zhang, Xue; Zhang, Binsheng

Published in:

Materials and Structures

Publication date:

2019

Document Version

Author accepted manuscript

Link to publication in ResearchOnline

Citation for published version (Harvard):

Rong, H, Dong, W, Zhang, X \& Zhang, B 2019, 'Size effect on fracture properties of concrete after sustained loading', Materials and Structures, vol. 52, no. 16, pp. 1-12.

\section{General rights}

Copyright and moral rights for the publications made accessible in the public portal are retained by the authors and/or other copyright owners and it is a condition of accessing publications that users recognise and abide by the legal requirements associated with these rights.

Take down policy

If you believe that this document breaches copyright please view our takedown policy at https://edshare.gcu.ac.uk/id/eprint/5179 for details of how to contact us. 

0

\title{
Size effect on fracture properties of concrete after sustained loading
}

\author{
Hua Rong ${ }^{1}$, Wei Dong ${ }^{2, *}$, Xue Zhang ${ }^{3}$, Binsheng Zhang ${ }^{4}$ \\ ${ }^{1}$ Senior Engineer, State Key Laboratory of Coastal and Offshore Engineering, Dalian University of
} Technology, Dalian 116024, P. R. China. \& National Test Centre of Quality and Safety Supervision for Industrial Buildings and Structures, Central Research Institute of Building and Construction, MCC, Beijing, 100088, P. R. China. Email: ronghuakeke@163.com

${ }^{2}$ Professor, State Key Laboratory of Coastal and Offshore Engineering, Dalian University of Technology, Dalian 116024, P. R. China.

*Corresponding author, E-mail: dongwei@dlut.edu.cn

(1)

${ }^{3}$ Lecturer, State Key Laboratory of Coastal and Offshore Engineering, Dalian University of Technology, Dalian 116024, P. R. China. E-mail: xuezhang@dlut.edu.cn

${ }^{4}$ Professor, Department of Civil Engineering and Environmental Management, School of Computing, Engineering and Built Environment, Glasgow Caledonian University, Glasgow G4 0BA, Scotland, United Kingdom. E-mail: Ben.Zhang@gcu.ac.uk (1)

Conflict of interest: The authors declare that they have no conflict of interest. 


\section{ABSTRACT} 0

To investigate the size effect on the fracture properties of concrete after sustained loading, concrete beams with three heights of $100 \mathrm{~mm}, 200 \mathrm{~mm}$ and $300 \mathrm{~mm}$ were first subjected to $30 \%$ peak load over 115 days. Thereafter, they were moved out from the loading frames and tested under standard static three-point bending (TPB) loading until failure. The initial fracture toughness, unstable fracture toughness, fracture energy and evolution of the fracture process zone were then derived based on the experimental results, and the size effect on these fracture properties of concrete after sustained loading were evaluated. The experimental results indicated that compared with the specimens under the static TPB tests without pre-sustained loading, the cracking initiation resistance for the concrete after sustained loading increased, resulting in the increase of the initial cracking load and initial fracture toughness. In particular, the tendency was more significant for the larger size specimens. By contrast, the effects of sustained loading on the unstable fracture toughness, fracture energy, critical crack length and FPZ evolution could be neglected. Furthermore, the size effects on the fracture characteristics, including the fracture energy, and the FPZ evolution were obvious for the concrete specimens both under static loading and after sustained loading.

Keywords: concrete beam, three-point bending, sustained loading, fracture toughness, fracture energy, size effect 
Delayed failure of concrete structures under sustained loading has a significant effect on the service performance and durability of the structures. Generally, it is considered that linear creep occurs in concrete structures under low load levels, which is caused by viscoelasticity of concrete. By contrast, under high load levels, crack growth interacts with viscoelasticity of the material, resulting in occurrence of nonlinear creep [1]. The crack rate dependence was introduced by Van Zijl et al. [2], which is characterised by the inverse analysis to calculate the time to failure under high sustained loading. The predicted results agreed well with the experimental observations [3]. In fact, creep has two potential effects on the fracture behaviour of concrete structures. Firstly, creep could lead to attention to academic and engineering communities. According to the research by Barpi and Valente appeared to be negligible, as indicated by Bažant and Xiang [7]. [6], the lifetime of concrete structures appeared to be an increasing function of size, and a critical height of $59 \mathrm{~cm}$ was observed. Far from the critical dimension, the size effect on the lifetime

The fracture parameters, e.g. the fracture toughness and facture energy, represent the cracking resistance and fracture characteristics of concrete and are generally considered as material properties 
for fracture analysis. The double- $K$ fracture theory was proposed by $\mathrm{Xu}$ and Reinhardt $[8,9]$ as a modified linear elastic fracture mechanics (LEFM) model to distinguish different cracking stages of concrete, where the fracture process of concrete can be divided into three stages using the initial fracture toughness $K_{\mathrm{IC}}^{\mathrm{ini}}$ and the unstable fracture toughness $K_{\mathrm{IC}}^{\mathrm{un}}$. According to the experimental and theoretical studies under static loading [8-11], these two fracture toughness parameters were size-independent and can be regarded as the material parameters to determine the cracking initiation and unstable propagation in concrete structures. Based on the initial fracture toughness, a crack propagation criterion [12-14] was proposed to determine the crack propagation during the fracture process of concrete. Meanwhile, the effects of loading rate on the double- $K$ fracture parameters were investigated and the results indicated that both $K_{\mathrm{IC}}^{\mathrm{ini}}$ and $K_{\mathrm{IC}}^{\mathrm{un}}$ increased with the increased loading rates [15]. In the case of low sustained loading, stress relaxation and re-distribution occur at the crack tip, even though there is no crack propagation at the creep stage. The variations of the stress field at the crack tip would change the cracking resistance of concrete and also affect the initial fracture toughness. However, it is not clarified whether or not the sustained loading affects the crack propagation length and the unstable fracture toughness corresponding to the critical fracture status.

Besides fracture toughness, fracture energy is also a significant fracture parameter to characterize the crack propagation resistance of concrete. Previous experimental studies [16-18] showed that the tested fracture energy would increase with the increased specimen size. Accordingly, two theories can be employed to explain the size effect: the size effect law [19] and the boundary effect model [20]. According to the fictitious crack model [21], there exists a fracture process zone (FPZ) ahead of a traction-free crack, where the cohesive stresses are transferred and energy is dissipated. Therefore, fracture energy is directly related to the FPZ, so that the size effect on fracture energy would be 
91 involved in the FPZ evolution. Based on the research by Wu et al. [22], the FPZ would increase

92 linearly until the full length was reached, and then decrease when the crack tip approached to the

surface of the specimen. Meanwhile, the ratio of the crack length $a$ to the specimen depth $D$,

corresponding to the full FPZ length, would decrease with the increased specimen size [23].

Accordingly, the size effect of the fracture energy could also be reflected when determining the

tension-softening constitutive law of concrete [24, 25]. Under sustained loading conditions, based on

the researches by Omar et al. [26] and Carpinteri et al. [27], the values of fracture energy under

sustained loading and static loading were similar. However, Saliba $[28,29]$ indicated that, due to the

consolidation of hardened cement paste, concrete could be strengthened under sustained loading so

that the measured fracture energy and strength slightly increased after sustained loading.

\section{Research significance}

The investigations from different researchers indicate that it still remains controversial whether the 
113 effects of sustained loading on the fracture properties of the concrete specimens with different sizes 114 were evaluated.

\section{Experimental program}

\section{Specimen preparations}

117 To investigate the size effect on the fracture properties of concrete, three series of TPB specimens 118 with similar geometries were measured in this study. The beam heights were $100 \mathrm{~mm}, 200 \mathrm{~mm}$ and $119300 \mathrm{~mm}$, respectively, with the ratio of the initial notch length to the depth, $a_{0} / D$, as 0.3 and the ratio 120 of the depth to the spans as 0.25 . The effect of the width was not considered here, so that the width of all specimens was chosen as $100 \mathrm{~mm}$ and the distance from the support to the edge of the specimen was chosen as $50 \mathrm{~mm}$. In this study, the specimen sizes were adopted as length $\times$ width $\times$ depth $(L \times$ $B \times D)=500 \mathrm{~mm} \times 100 \mathrm{~mm} \times 100 \mathrm{~mm}, 900 \mathrm{~mm} \times 100 \mathrm{~mm} \times 200 \mathrm{~mm}$ and $1300 \mathrm{~mm} \times 100 \mathrm{~mm} \times$ $300 \mathrm{~mm}$, respectively. After demolding, all the beam specimens were polished mechanically until the designed sizes were achieved. Thereafter, the beam specimens were processed by using a diamond saw to form the initial notch with the wide of $2 \mathrm{~mm}$ and the length of $30 \%$ of the beam height. The mix proportions of the concrete were $1: 0.60: 2.01: 3.74$ (cement : water : sand : aggregate) by weight and the maximum coarse aggregate size was $10 \mathrm{~mm}$. The specimens were demoulded 24 hours after casting and then stored in the standard curing room with $23^{\circ}$ and $90 \%$ relative humidity for three months to avoid the effects of the autogenous shrinkage at early age and the increased strength on the experimental investigations. The experimental data (Exp.) of the mechanical properties including the elastic modulus $E$, the splitting tensile strength $f_{\mathrm{t}}$, and the uniaxial compressive strength $f_{\mathrm{c}}$ at the ages of 28 and 90 days are listed in Table 1 . In addition, their statistical results including the average values (Av.) and the standard deviations (S.D.) are calculated 
135 accordingly. It can be seen that the standard deviations of the experimental data in Table 1 are 136 relatively small compared with the average values and the calculated average values show the 137 coincident tendency, i.e. the mechanical properties of concrete at the age of 90 days are slightly 138 larger than those at the age of 28 days. Meanwhile, comparing these material properties between the 139 ages of 90 and 205 days shows that there are no significant variations observed. This indicates that 140 the mechanical properties of concrete fairly kept constant after the 90-day curing.

141

Table 1 Mechanical properties of concrete

\begin{tabular}{cccccccccccccccc}
\hline $\begin{array}{c}\text { Age } \\
\text { (days) }\end{array}$ & \multicolumn{1}{c}{ Exp.1 } & Exp.2 & Exp.3 & Av. & S.D. & Exp.1 & Exp.2 & Exp.3 & Av. & S.D. & Exp.1 & Exp.2 & Exp.3 & Av. & S.D. \\
\hline 28 & 31.9 & 32.1 & 34.7 & 32.9 & 1.28 & 2.0 & 2.3 & 2.3 & 2.2 & 0.14 & 36.8 & 38.6 & 36.2 & 37.2 & 1.02 \\
90 & 36.2 & 35.8 & 37.2 & 36.4 & 0.59 & 2.6 & 2.5 & 2.4 & 2.5 & 0.08 & 45.9 & 47.2 & 45.8 & 46.3 & 0.64 \\
205 & 35.8 & 33.6 & 33.5 & 34.3 & 1.06 & 2.7 & 2.4 & 2.4 & 2.5 & 0.14 & 44.8 & 47.5 & 45.1 & 45.8 & 1.21 \\
\hline
\end{tabular}

143 In addition, to calibrate the applied load in the followed creep tests, the standard TPB tests were 144 conducted on concrete specimens with three sizes at the age of 90 days. For each series, three 145 specimens were prepared and the average results of the $P-C M O D$ curves for S-, $\mathrm{M}$ - and L-series are 146 shown in Fig 1. The average values of the peak load $P_{\max }$ were determined as $3.81 \mathrm{kN}, 7.01 \mathrm{kN}$ and $147 \quad 10.34 \mathrm{kN}$, respectively, which were used to pre-set $P_{\max }$ on the creep specimens with the same 148 geometry. Meanwhile, three more specimens for each condition were cast at the same time and kept 149 under the same curing conditions without being loaded, named as "aging specimens". The specimens 150 with depths of $100 \mathrm{~mm}, 200 \mathrm{~mm}$ and $300 \mathrm{~mm}$ were denoted as S-, M- and L-series. For example, 151 "M-30-1" denotes the TPB beam specimen 1 with sizes of $900 \mathrm{~mm} \times 100 \mathrm{~mm} \times 200 \mathrm{~mm}$ under the $15230 \% P_{\max }$ loading level. 


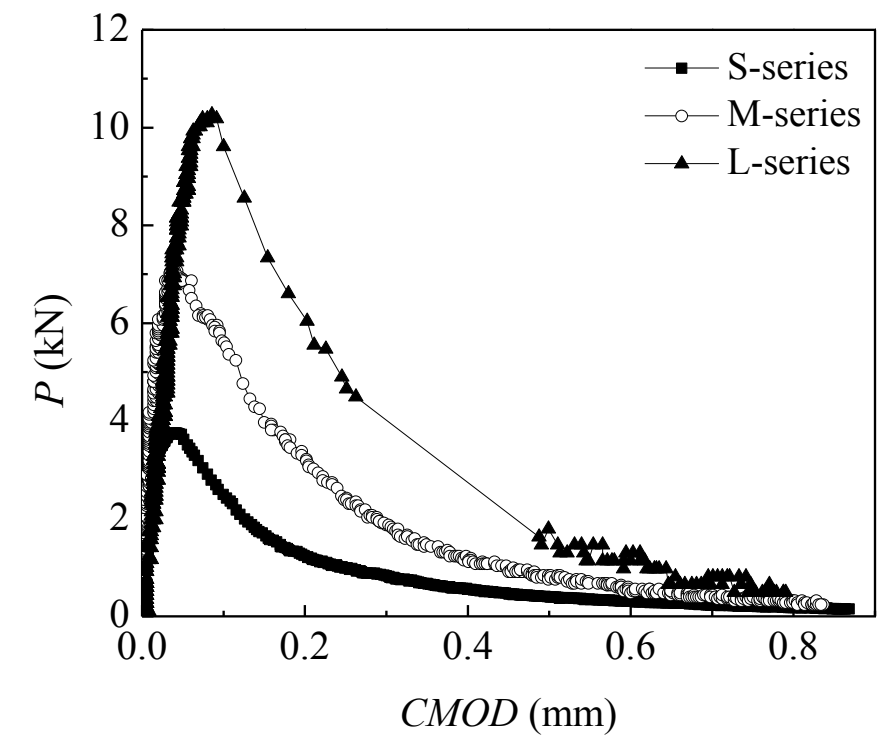

Fig. 1. $P$ - $C M O D$ curves for TPB specimens with different sizes

\section{Creep tests}

The basic creep tests under TPB loading were performed first. In order to ensure only the basic creep to be measured in the tests, a double-layer aluminium tape was used to seal all the surfaces of the specimens to prevent the moisture dissipation. It has been proved that the use of a double-layer aluminum tape to seal the specimens can effectively prevent the dissipation of the interior moisture from the specimen surface [1]. Also, this method is adopted by the American Association of State Highway and Transportation Officials (i.e. AASHTO PP34-99: Standard Practice for Cracking Tendency Using a Ring Specimen) and American Society for Testing Material (i.e. the ASTM C1581/C1581M-09a: Standard Test Method for Determining Age at Cracking and Induced Tensile Stress Characteristics of Mortar and Concrete under Restrained Shrinkage) to assess the cracking tendency of concrete under restrained shrinkage. Meanwhile, the steel loading frames with different sizes were designed for performing the creep tests. Fig.2 illustrates the typical set-up for Specimen S-30-1 under the creep test. The load cell was put between the frame and the specimen and connected to a bolt, and the load was applied by turning the bolt. For the S-, M- and L series specimens subjected to $30 \% P_{\max }$, the bolts were turned until the load levels of $1.14 \mathrm{kN}, 2.10 \mathrm{kN}$ and 
1713.10 were reached, respectively. The data acquisition system with a digital display was used to record 172 the real-time load readings. The loading point displacement $(\delta)$ and CMOD were measured using the 173 dial gauges (see Fig. 2). The creep tests were conducted inside an environmental chamber with $23^{\circ}$ 174 and $60 \%$ relative humidity. During the creep tests, the loads would be increased to the pre-set values 175 if they decreased by $2 \%$. The loading duration for the creep tests was 115 days, and the mechanical properties of concrete at the age of 205 days $(90+115$ days $)$ are also listed in Table 1.

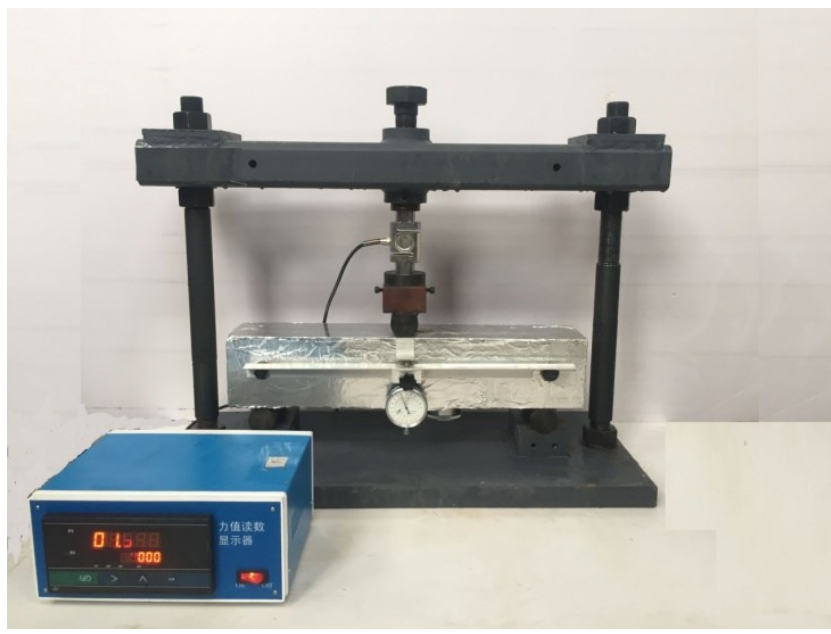

Fig. 2. Set-up for Specimen S-30-1 under the creep test

Fig. 3 illustrates the loading point displacement versus time curves ( $\delta-t$ curves) for the S-, M- and L-series specimens. It can be seen that the creep deformation increased with the increased specimen size. For each size specimen, the creep deformation increased significantly in the first 10 days of loading, and then the increase became slow until an approximate stable status was reached two months after the loading. As shown in Fig. 2, the mechanical dial gauges were used to measure the loading point displacements during the creep tests, whose measurement resolution is 1 micrometer. From Fig. 3, it can be seen that the variations of the loading point displacements could be detected for both the rapid growth stage at early age and the stabilization stage at later age. Therefore, this resolution of 1 micrometer would allow for accurate measurements of the loading point displacements during the creep tests. It should be noted that, due to the effect of the measurement 
resolution of the device, the displacement variations could not be monitored when the deflected values were smaller than 1 micrometer. Meanwhile, the B3 model [30] was utilised to predict the creep deformation over time for the S-, M- and L-series specimens. The predicted results showed reasonably good agreements with the experimental data, which indicates that the B3 model is appropriate for assessing the creep deformation of concrete specimens with different sizes under low sustained loading.

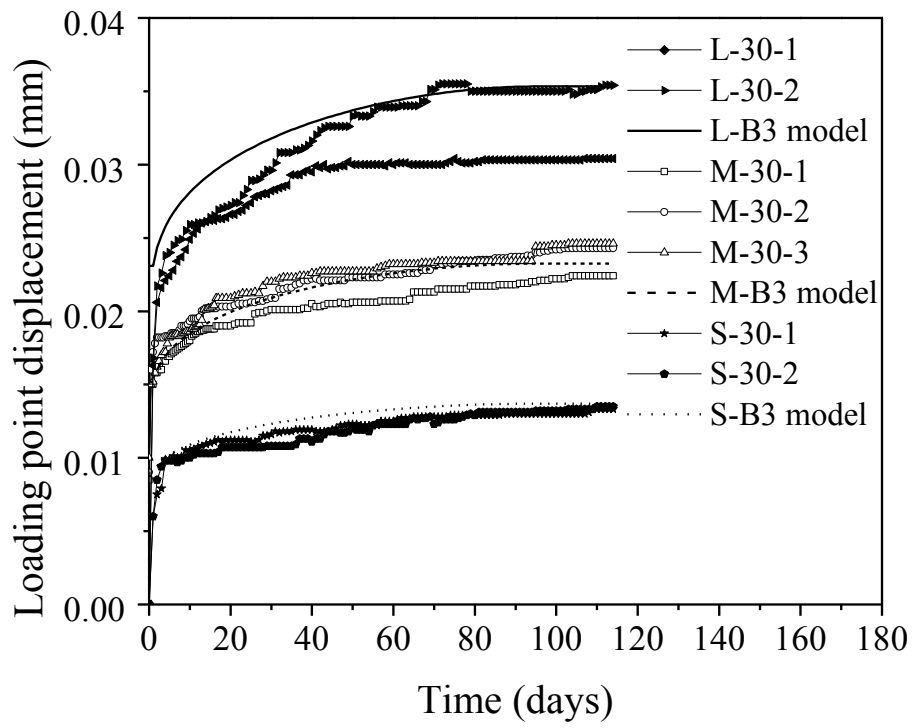

Fig. 3. Loading point displacement versus time curves in the creep tests

\section{Standard TPB tests}

After 115 days of sustained loading, the specimens in the creep tests were moved out from the loading frames and then immediately tested under the standard TPB loading. A $250 \mathrm{kN}$ closed loop servo-controlled MTS testing machine was used for loading the TPB beams, including the creep and aging specimens prepared in this study, at a displacement rate of $0.048 \mathrm{~mm} / \mathrm{min}$. A clip gauge was mounted on the bottom of each beam to measure the $C M O D$ during loading. In order to obtain the crack propagation length, the clip gauges were placed equidistantly along the ligament length to measure the crack opening displacements. The experimental set-up for the standard TPB tests and the arrangements of the clip gauges are illustrated in Figs. 4(a) and (b), respectively. 


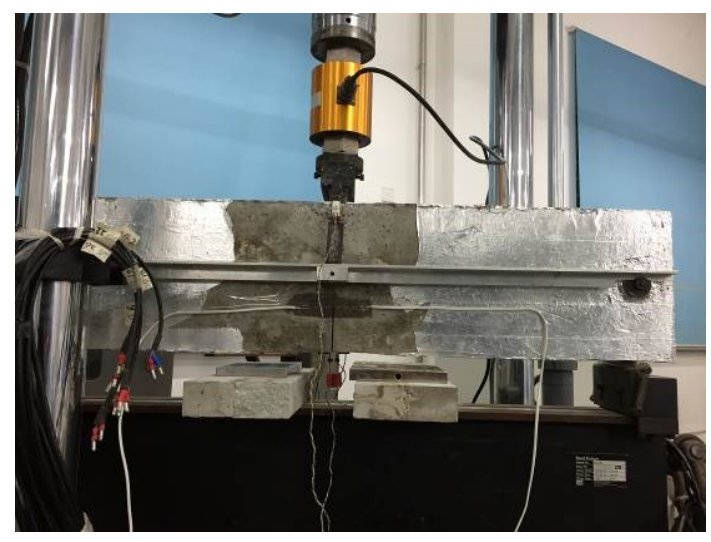

(a) Measuring loading point displacement and $C M O D$

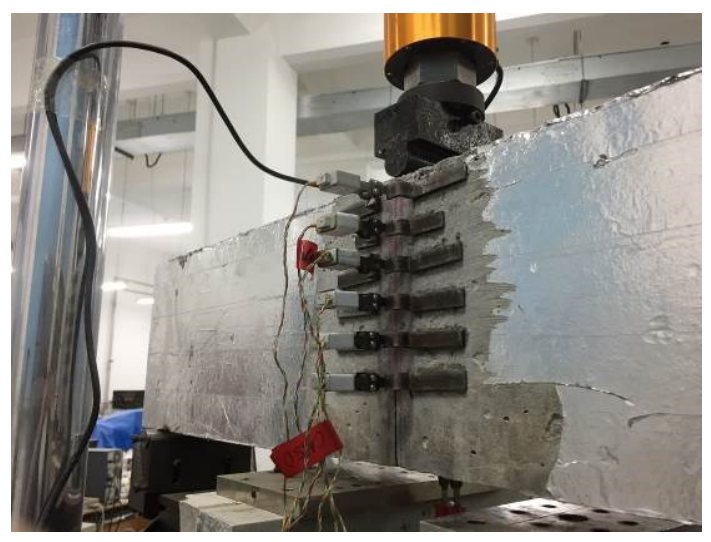

(b) Measuring crack opening displacement

Fig. 4. Experimental set-up for the standard TPB tests

The displacement at the crack initiation, $w_{\text {ini, }}$ could be calibrated by measuring the crack tip opening displacement $(C T O D)$ with respect to the initial cracking load on the aging specimen. According to the research by $\mathrm{Xu}$ et al. [8], the crack tip opening displacement (CTOD) at the crack initiation can be regarded to be size-independent. Therefore, the average displacement at the crack initiation, $w_{\text {ini, }}$ determined from the S-series TPB specimens as $8.423 \times 10^{-6} \mathrm{~m}$, was used to characterize the crack initiation for all the S-, M- and L-series specimens. To measure the initial cracking load, four strain gauges were symmetrically pasted on both sides of the specimen surface, $5 \mathrm{~mm}$ away from the tip of the pre-notch. Once a new crack began to initiate, the measured strains from the strain gauges would drop rapidly due to the sudden release of the stored strain energy at the tip of the pre-crack. Based on the measured $C M O D$ s and crack opening displacements $(w)$ at the different positions along the ligament, an approximately linear distribution of the crack opening displacements was obtained. Taking Specimen S-30-1 as an example, the crack opening displacements approximately linearly distributed along the crack surface, as shown in Fig. 5. Furthermore, by comparing $w_{\text {ini }}$ and $w$, the crack tip can be determined, which is marked as Point "O" in Fig. 5. Accordingly, the crack propagation lengths with respect to various loading points could also be obtained from the positions of the derived crack tip during the complete fracture process. By introducing the tension-softening 
constitutive law of concrete, the FPZ evolution in the crack propagation process could be derived.

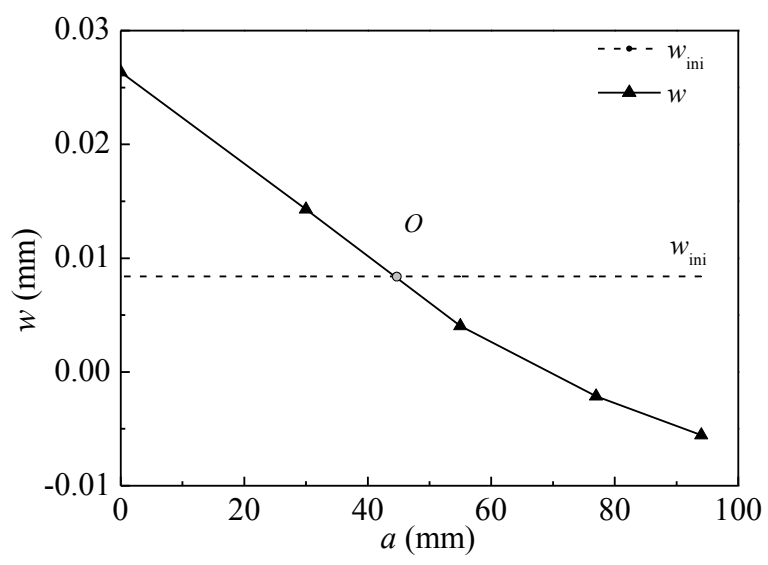

Fig. 5. Determination of the crack tip using clip gauges

\section{Results and discussion}

\section{Effects of sustained loading on the fracture properties}

According to the creep deformations illustrated in Fig. 3, the initial cracks did not propagate in the creep tests because the stable displacements for the specimens were observed. For some concrete structures, the load capacity could increase after a low sustained loading, e.g. the variations of the water lever for the gravity dams. Therefore, the cracking resistance of concrete structures after a sustained loading is of concern to engineering and academic fields. Based on the sudden drop of the strain around the initial crack tip, the values of the initial cracking load $P_{\text {ini }}$ for different specimen sizes were determined from the standard TPB tests, as shown in Table 2. Taking Specimen M-aging-1 as an example, Fig. 6 illustrates the strain variations at the pre-notch tip, where Points A and B correspond to the initial and peak loads, respectively. Compared with the aging specimens, Table 2 indicates that the initial cracking load increased for the specimens subjected to pre-sustained loading. Meanwhile, the increase is more significant for the specimens with larger sizes. For the S-, M- and L-series specimens, the growths in $P_{\text {ini }}$ were $7.5 \%, 54.2 \%$ and $62.7 \%$, respectively. By 
245 contrast, the effect of sustained loading on the peak load is not significant, compared with the aging 246 specimens, the changes in $P_{\max }$ being $-1.95 \%, 18.23 \%$ and $11.17 \%$ for the S-, $\mathrm{M}$ - and L-series 247 specimens, respectively.

Table 2. Experimental results for the TPB tests

\begin{tabular}{|c|c|c|c|c|c|c|c|c|}
\hline \multirow{2}{*}{ Specimens } & \multirow{2}{*}{$\begin{array}{c}P_{\text {ini }} \\
(\mathrm{kN}) \\
\end{array}$} & \multirow{2}{*}{$\begin{array}{l}P_{\max } \\
(\mathrm{kN})\end{array}$} & \multicolumn{2}{|c|}{$a_{\mathrm{c}}(\mathrm{mm})$} & \multirow{2}{*}{$\begin{array}{c}K_{\mathrm{IC}}^{\mathrm{ini}} \\
\left(\mathrm{MPa} \cdot \mathrm{m}^{1 / 2}\right)\end{array}$} & \multirow{2}{*}{$\begin{array}{c}K_{\mathrm{IC}}^{\mathrm{un}} \\
\left(\mathrm{MPa} \cdot \mathrm{m}^{1 / 2}\right)\end{array}$} & \multirow{2}{*}{$\begin{array}{c}G_{\mathrm{f}} \\
(\mathrm{N} / \mathrm{m})\end{array}$} & \multirow{2}{*}{$\begin{array}{c}L_{\mathrm{ch}} \\
(\mathrm{mm})\end{array}$} \\
\hline & & & Cal. & Exp. & & & & \\
\hline S-aging-1 & 2.66 & 3.56 & 52.08 & 55.15 & 0.51 & 1.42 & 81.71 & 464.02 \\
\hline S-aging-2 & 2.53 & 3.68 & 48.10 & 50.63 & 0.49 & 1.27 & 102.22 & 580.50 \\
\hline S-aging-3 & 2.51 & 3.61 & 49.13 & 50.25 & 0.49 & 1.22 & 87.43 & 496.51 \\
\hline Mean & 2.55 & 3.59 & 49.77 & 52.01 & 0.50 & 1.28 & 90.45 & 513.66 \\
\hline S.D. & 0.07 & 0.05 & 1.69 & 2.23 & 0.01 & 0.08 & 8.64 & 49.07 \\
\hline \multirow{2}{*}{$\begin{array}{ll}\text { C.I. } & \text { Lower } \\
\text { Upper }\end{array}$} & 2.49 & 3.56 & 47.75 & 49.34 & 0.49 & 1.20 & 80.11 & 454.91 \\
\hline & 2.62 & 3.68 & 51.79 & 54.68 & 0.51 & 1.41 & 100.80 & 572.44 \\
\hline S-30-1 & 2.88 & 3.79 & 50.98 & 52.78 & 0.55 & 1.31 & 88.64 & 503.38 \\
\hline S-30-2 & 2.61 & 3.25 & 54.36 & 54.90 & 0.50 & 1.29 & 85.64 & 486.34 \\
\hline Mean & 2.74 & 3.52 & 52.67 & 53.84 & 0.53 & 1.30 & 87.14 & 494.86 \\
\hline S.D. & 0.135 & 0.27 & 1.69 & 1.06 & 0.03 & 0.01 & 1.5 & 8.52 \\
\hline \multirow{2}{*}{ C.I. Upper } & 2.55 & 3.12 & 50.19 & 52.29 & 0.49 & 1.29 & 84.94 & 482.37 \\
\hline & 2.94 & 3.92 & 55.15 & 55.39 & 0.56 & 1.31 & 89.34 & 507.35 \\
\hline M-aging-1 & 4.13 & 6.76 & 79.72 & 83.66 & 0.56 & 1.19 & 97.07 & 551.25 \\
\hline M-aging-2 & 4.14 & 7.40 & 87.60 & 91.23 & 0.56 & 1.46 & 100.98 & 573.45 \\
\hline M-aging-3 & 4.46 & 6.70 & 79.54 & 86.51 & 0.61 & 1.18 & 88.22 & 500.99 \\
\hline Mean & 4.24 & 6.95 & 82.29 & 87.13 & 0.58 & 1.28 & 95.42 & 541.88 \\
\hline S.D. & 0.15 & 0.32 & 3.76 & 3.12 & 0.02 & 0.13 & 5.34 & 30.31 \\
\hline \multirow{2}{*}{ C.I. Upper } & 4.06 & 6.57 & 77.79 & 83.40 & 0.55 & 1.12 & 89.03 & 505.60 \\
\hline & 4.43 & 7.33 & 86.79 & 90.87 & 0.60 & 1.43 & 101.81 & 578.19 \\
\hline M-30-1 & 6.59 & 8.53 & 76.78 & 80.17 & 0.90 & 1.45 & 90.62 & 514.62 \\
\hline M-30-2 & 7.11 & 8.77 & 81.31 & 86.68 & 0.97 & 1.58 & 102.96 & 584.70 \\
\hline M-30-3 & 5.93 & 8.21 & 82.14 & 89.87 & 0.81 & 1.50 & 90.12 & 511.78 \\
\hline Mean & 6.54 & 8.50 & 80.08 & 85.57 & 0.89 & 1.51 & 94.57 & 537.05 \\
\hline S.D. & 0.48 & 0.23 & 2.36 & 4.04 & 0.06 & 0.05 & 5.94 & 33.73 \\
\hline \multirow{2}{*}{$\begin{array}{ll}\text { C.I. } & \text { Lower } \\
\text { Upper }\end{array}$} & 5.97 & 8.23 & 77.26 & 80.74 & 0.81 & 1.45 & 87.46 & 496.65 \\
\hline & 7.12 & 8.78 & 82.90 & 90.41 & 0.97 & 1.57 & 101.68 & 577.41 \\
\hline L-aging-1 & 4.54 & 9.00 & 128.17 & 134.40 & 0.54 & 1.40 & 132.53 & 752.62 \\
\hline L-aging-2 & 4.99 & 9.98 & 127.76 & 129.67 & 0.55 & 1.55 & 141.63 & 804.30 \\
\hline Mean & 4.77 & 9.49 & 131.63 & 132.04 & 0.55 & 1.47 & 137.08 & 778.46 \\
\hline S.D. & 0.23 & 0.49 & 0.21 & 2.37 & 0.01 & 0.075 & 4.55 & 25.84 \\
\hline \multirow{2}{*}{$\begin{array}{ll}\text { C.I. } & \text { Lower } \\
\text { Upper }\end{array}$} & 4.44 & 8.77 & 127.66 & 128.57 & 0.54 & 1.37 & 130.41 & 740.57 \\
\hline & 5.09 & 10.21 & 128.27 & 135.50 & 0.55 & 1.58 & 143.75 & 816.35 \\
\hline L-30-1 & 7.39 & 9.65 & 126.90 & 127.54 & 0.82 & 1.49 & 146.81 & 833.72 \\
\hline
\end{tabular}




\begin{tabular}{|c|c|c|c|c|c|c|c|c|}
\hline L-30-2 & 8.14 & 10.46 & 130.93 & 136.02 & 0.90 & 1.68 & 147.63 & 838.37 \\
\hline Mean & 7.76 & 10.06 & 128.28 & 131.78 & 0.86 & 1.59 & 147.22 & 836.05 \\
\hline S.D. & 0.38 & 0.41 & 2.02 & 4.24 & 0.04 & 0.10 & 0.41 & 2.33 \\
\hline Lower & 7.22 & 9.46 & 125.96 & 125.56 & 0.80 & 1.45 & 146.62 & 832.64 \\
\hline Upper & 8.31 & 10.64 & 131.87 & 138.00 & 0.92 & 1.72 & 147.82 & 839.45 \\
\hline
\end{tabular}

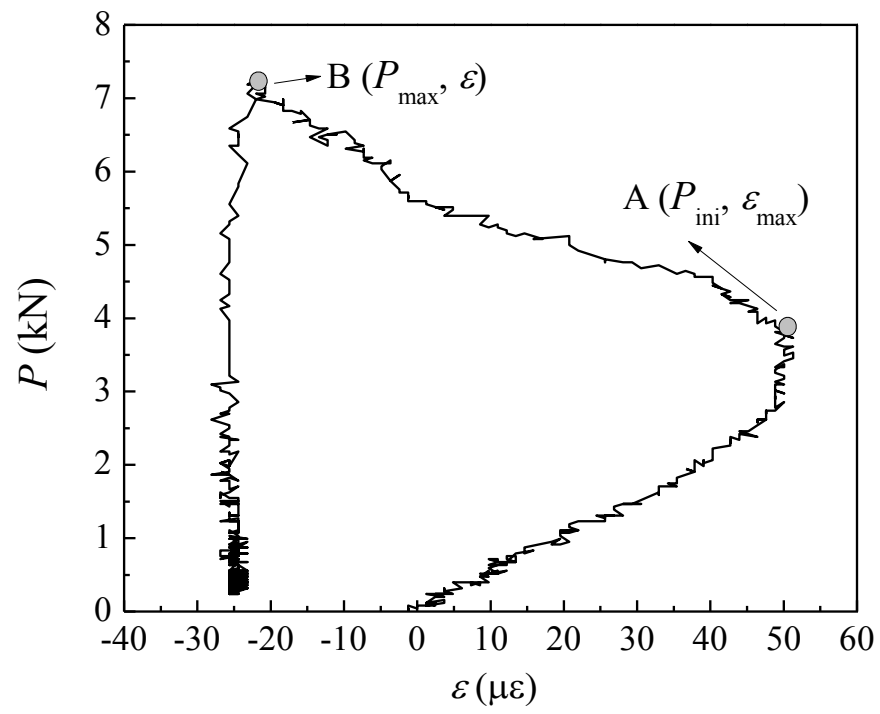

Fig. 6. Strain variations at the pre-notch tip of Specimen M-aging-1

252 The values of the critical crack length $a_{\mathrm{c}}$ obtained from the experimental measurements and analytical method [9] are also included in Table 2 . The equation for analytically calculating $a_{\mathrm{c}}$ is 254 given as follows:

$$
a_{\mathrm{c}}=\frac{2}{\pi}\left(D+H_{0}\right) \text { a rct } \sqrt{\frac{B \cdot E \cdot C M O_{\mathrm{c}}}{32 P_{\mathrm{max}}}} \frac{D}{3} \quad-\dashv 1 A
$$

where $C M O D_{\mathrm{c}}$ is the critical crack mouth opening displacement measured in the tests, and $H_{0}$ is the 257 thickness of the knife edge and is equal to $3 \mathrm{~mm}$ in this study.

The values of $a_{\mathrm{c}}$ in Table 2 indicate that the analytical and experimental results are in a reasonably good agreement, and confirm that the analytical equation from LEFM is appropriate for determining the critical crack length after low sustained loading. After obtaining the peak loads and the critical crack propagation lengths from the tests, the initial and unstable fracture toughnesses, $K_{\mathrm{IC}}^{\mathrm{ini}}$ and $K_{\mathrm{IC}}^{\mathrm{un}}$, 
can be calculated [9] as

$$
\begin{aligned}
& K_{\mathrm{IC}}^{\mathrm{ini}}=\frac{3 P_{\mathrm{ini}} S}{2 D^{2} B} \sqrt{a_{0}} F_{2}\left(\frac{a_{0}}{D}\right) \\
& K_{\mathrm{IC}}^{\mathrm{un}}=\frac{3 P_{\text {max }} S}{2 D^{2} B} \sqrt{a_{\mathrm{c}}} F_{2}\left(\frac{a_{\mathrm{c}}}{D}\right)
\end{aligned}
$$

where $S$ is the span of the specimens and $F_{2}\left(\frac{a}{D}\right)$ can be calculated from the following equation:

$$
F_{2}\left(\frac{a}{D}\right)=\frac{1.99-\left(\frac{a}{D}\right)\left(1-\frac{a}{D}\right)\left[2.15-3.93\left(\frac{a}{D}\right)+2.7\left(\frac{a}{D}\right)^{2}\right]}{\left(1+2 \frac{a}{D}\right)\left(1-\frac{a}{D}\right)^{3 / 2}}
$$

Noted that $a$ in Eq. (4) should be substituted by $a_{0}$ and $a_{\mathrm{c}}$ for the solution of $K_{\mathrm{IC}}^{\mathrm{ini}}$ and $K_{\mathrm{IC}}^{\mathrm{un}}$, respectively.

The values of $K_{\mathrm{IC}}^{\mathrm{ini}}$ and $K_{\mathrm{IC}}^{\mathrm{un}}$ for all specimens are listed in Table 2. It can be seen that there are no significant size effects on the two fracture toughnesses obtained under static loading, which confirms

271 the finding obtained by $\mathrm{Xu}$ et al. [8]. However, the scenarios are different for the specimens with 272 various sizes after sustained loading. Compared with the aging specimens, the values of $K_{\mathrm{IC}}^{\mathrm{ini}}$ for the 273 S-, M- and L-serials specimens after sustained loading increased by $6.0 \%, 53.5 \%$ and $56.4 \%$, respectively. With the increased specimen size, the initial fracture toughness was significantly 275 enhanced. By contrast, the effect of the specimen size on the unstable fracture toughness $K_{\mathrm{IC}}^{\mathrm{un}}$ was not 276 prominent, with net increases of $1.6 \%, 18 \%$, and $0.8 \%$ for the S-, M- and L-serials specimens only.

277 It should be noted that the double- $K$ theory [9] was employed in the analyses, so that the variation 278 tendencies for $K_{\mathrm{IC}}^{\mathrm{ini}}$ and $K_{\mathrm{IC}}^{\mathrm{un}}$ matched those for $P_{\mathrm{ini}}$ and $P_{\max }$. Comparing the measured and calculated 279 values of $a_{\mathrm{c}}$ indicates that the double- $K$ theory is fairly appropriate for determining the fracture properties of concrete at the critical status after low sustained loading. Accordingly, $K_{\mathrm{IC}}^{\mathrm{un}}$ is a fracture 
281 parameter governing the crack unstable propagation. Thus, the calculated $K_{\mathrm{IC}}^{\mathrm{un}}$ using the double- $K$ theory would be available if considering the negligible effect of low sustained loading. However, $K_{\mathrm{IC}}^{\mathrm{ini}}$

283 is a fracture parameter governing the resistance on the crack initiation. Even under a low sustained 284 loading, the stress re-distribution would occur at the tip of the pre-notch and this cannot be reflected 285 in the analyses based on the double- $K$ theory. Consequently, in the case of $K_{\mathrm{IC}}^{\mathrm{in}}$, the double- $K$ theory 286 may be not appropriate, i.e. the calculated results of $K_{\mathrm{IC}}^{\mathrm{ini}}$ may not be convincing. The work 287 considering the effect of stress re-distribution at the tip of the pre-notch will be conducted in the 288 further study.

289 Besides the initial and unstable fracture toughnesses, the fracture energy $G_{\mathrm{f}}$ is also an important 290 fracture parameter for concrete, which is defined as the required energy for creating the cracking area 291 and can be calculated using the following equation recommended by RILEM [31] as:

$$
G_{\mathrm{f}}=\frac{W_{\mathrm{f}}}{A_{\text {lig }}}=\frac{W_{0}+m g \delta_{0}}{B\left(D-a_{0}\right)}
$$

where $W_{\mathrm{f}}$ is the total absorbed energy, $A_{\text {lig }}$ is the ligament area, $W_{0}$ is the area under the measured load-deformation curve, $m g$ is the self-weight of the specimen, and $\delta_{0}$ is the loading-point displacement at failure.

296 The obtained values of $G_{\mathrm{f}}$ are listed in Table 2. With the increased specimen size, the values of $G_{\mathrm{f}}$ 297 increased under the static loading, and this can be explained by the models for the size and boundary 298 effects $[19,20]$. Compared with the results under static loading, the fracture energy was not affected 299 by low sustained loading but increased with the increased specimen sizes.

300 To verify the reliability of the conclusions on the size effect of fracture properties, the standard 301 deviations (S.D.) and the confidence intervals (C.I.) with a confidence level of 95\% are calculated 302 for all the configurations, which are listed in Table 2. It can be seen from the table that the standard 
deviations are relatively small, i.e. less than $10 \%$ of the corresponding average values for all the configurations. In addition, by comparing the confidence intervals (the lowers or the uppers) between different configurations, the conclusions on the size effect of fracture properties can also be obtained, which agree well with those obtained based on only the average values.

\section{Effects of sustained loading on the FPZ evolution}

According to the measuring method introduced in this study, the crack propagation lengths and the opening displacements with respect to various loading stages can be determined using clip gauges. Furthermore, a tension softening constitutive law was introduced to characterise the relationship between the crack opening displacement $w$ and the cohesive stress $\sigma$. According to the fictitious crack model [21], the nonlinear softening characteristics of the FPZ in concrete can be described using the $\sigma-w$ relationship, where the stress-free crack opening displacement $w_{0}$ governs the FPZ ending. Thus, the FPZ length can be determined as the distance from the crack tip to the position of stress-free crack. In this study, the bilinear $\sigma-w$ relationship was adopted, as illustrated in Fig. 7.

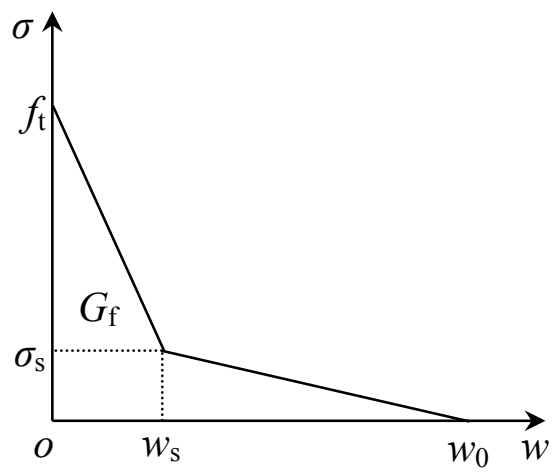

Fig. 7. Bilinear $\sigma-w$ concrete softening curve

According to Petersson [32], the parameters $\sigma_{\mathrm{s}}, w_{\mathrm{s}}$ and $w_{0}$ in this figure can be determined as:

$$
\sigma_{\mathrm{s}}=f_{\mathrm{t}} / 3
$$




$$
w_{\mathrm{s}}=0.8 G_{\mathrm{f}} / f_{\mathrm{t}}
$$

$$
w_{0}=3.6 G_{\mathrm{f}} / f_{\mathrm{t}}
$$

323 where $w_{\mathrm{s}}$ and $\sigma_{\mathrm{s}}$ are the crack opening displacement and the cohesive stress at the break-point of the 324 bilinear $\sigma-w$ relationship. According to the experimental results of $G_{\mathrm{f}}$ and $f_{\mathrm{t}}$, the bilinear $\sigma-w$ 325 relationship can be determined, which could be employed to quantify the FPZ length during the 326 loading process. Figs. 8 (a) to (c) illustrate the FPZ evolution for the S-, M- and L-series specimens, 327 respectively. For a vibrant comparison between the static and creep loading conditions, the average 328 curve was used for each loading condition. From Fig. 8, it can be seen that for each specimen size, the FPZ length increased linearly with the crack propagation, and then decreased after reaching a full evolution of the FPZ. The values of $\Delta a /\left(D-a_{0}\right)$ for the full FPZ length of the S-aging-, M-aging-and L-aging-series specimens were $0.89,0.83$ and 0.77 , respectively. Accordingly, the full FPZ lengths for the three series specimens were determined as $61.5 \mathrm{~mm}, 116.7 \mathrm{~mm}$ and $161.4 \mathrm{~mm}$. Although the ratio of $\Delta a /\left(D-a_{0}\right)$ decreased due to the boundary effect for the larger specimens, the full FPZ length still increased with the increased specimen size. Hence, the crack propagation in larger size specimens needs to overcome more resistance caused by the cohesive characteristics of concrete, resulting in the enhancement of fracture energy. Comparing with the aging specimens indicates that the FPZ evolution for the creep specimens showed similar variation trends. Thus, it can be seen that the effects of low sustained loading on the fracture energy and the FPZ evolution could be neglected, while the size effects still exist for the concrete after low sustained loading. Moreover, vertical cracks formed along the ligament length for all S-, M- and L-series specimens under TPB loading. To show the final crack patterns of the TPB specimens, the patterns for the S-creep specimens, as an example, have been illustrated in Fig. 9. 
343

344

345

346

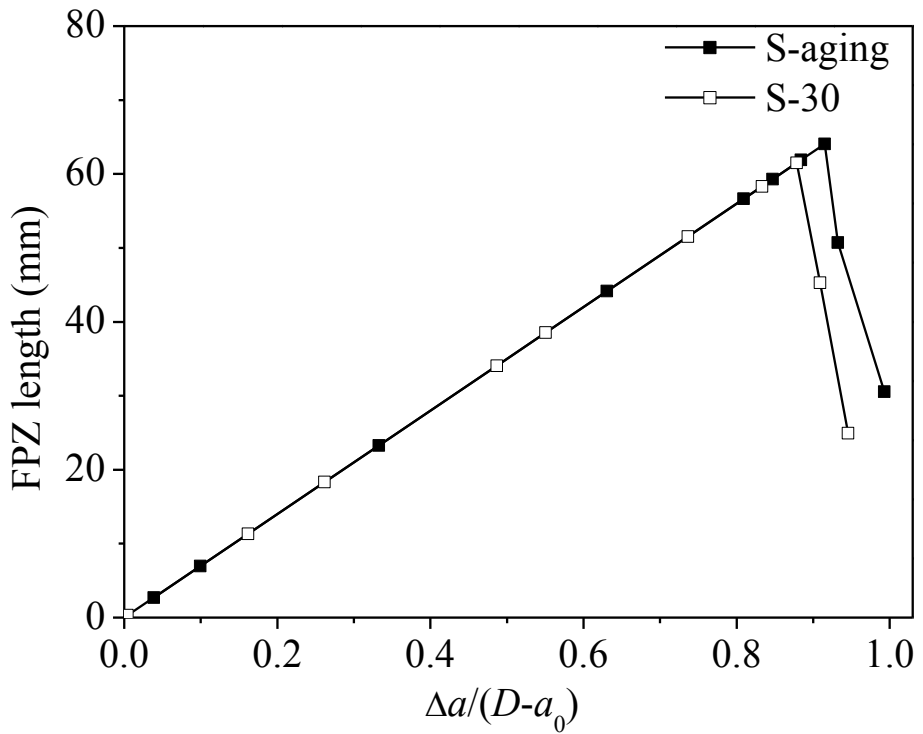

(a) S-series specimens

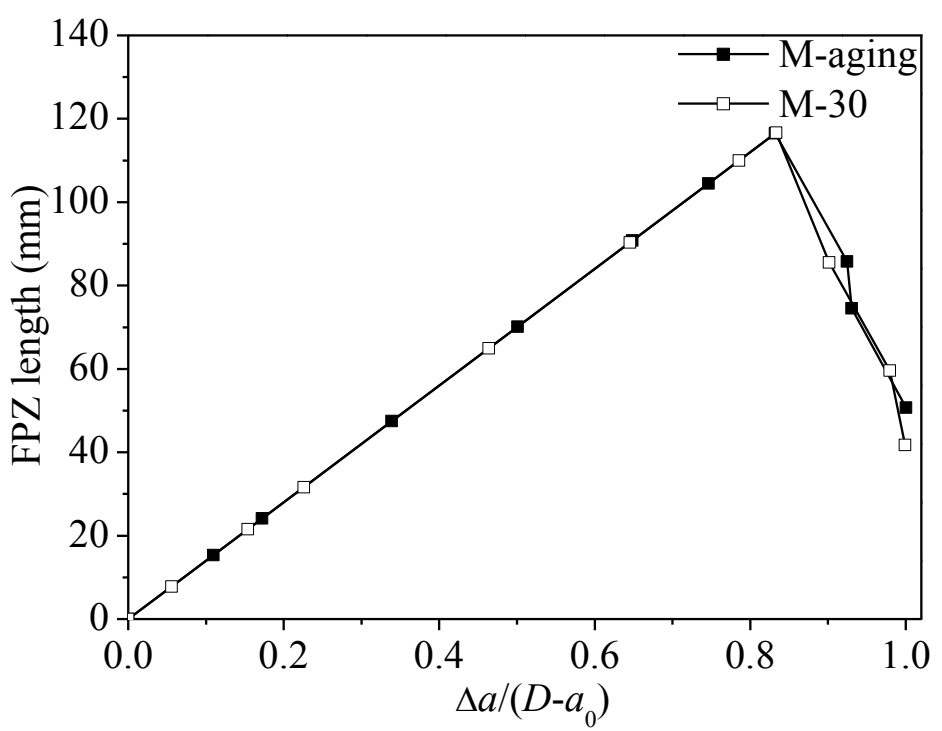

(b) M-series specimens 


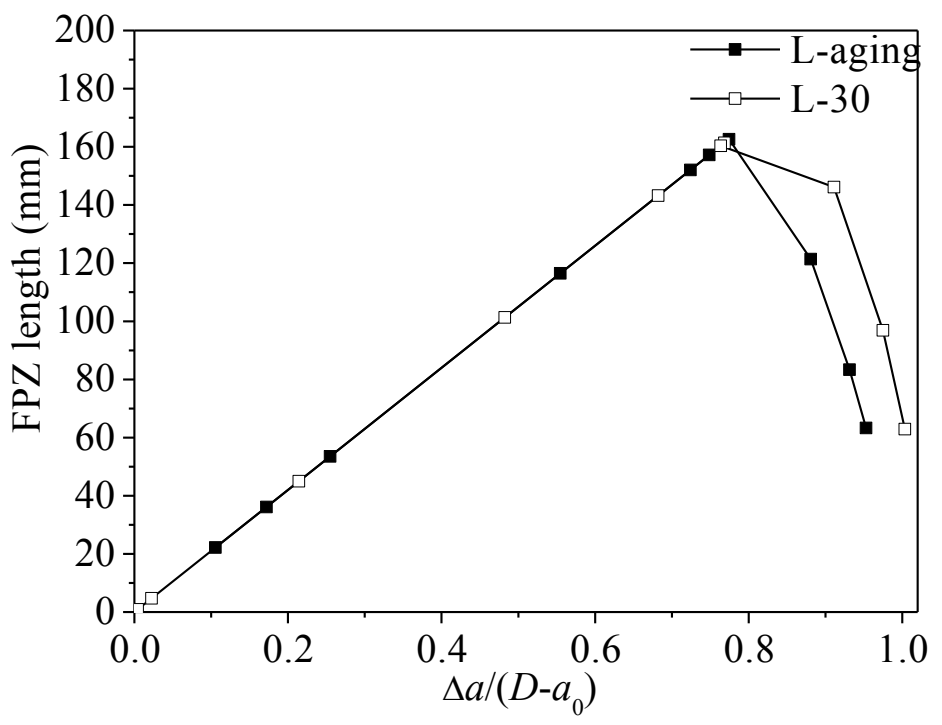

(c) L-series specimens

Fig. 8. FPZ evolutions for the S-, M-, and L-series specimens

350

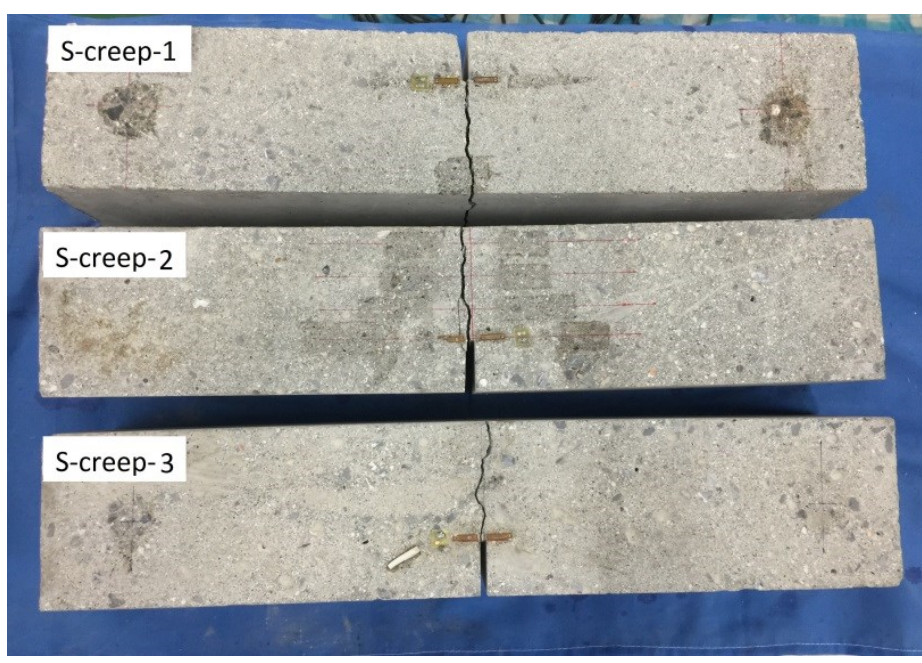

Fig. 9. Final crack patterns of the S-creep specimens

353 The characteristic length $L_{\mathrm{ch}}$ in mm was used to quantify the brittleness of the concrete specimens 354 and is defined as

$$
L_{\mathrm{ch}}=\frac{E G_{\mathrm{F}}}{f_{\mathrm{t}}^{2}}
$$


356 A small characteristic length indicates a larger brittleness of the material. The results of $L_{\mathrm{ch}}$ are listed

357 in Table 2. It can be seen that the values of $L_{\mathrm{ch}}$ increased with the increased specimen size. For the aging specimens with the depths of $100 \mathrm{~mm}, 200 \mathrm{~mm}$ and $300 \mathrm{~mm}$, the mean values of $L_{\mathrm{ch}}$ were obtained as $513.66 \mathrm{~mm}, 541.88 \mathrm{~mm}$ and $778.46 \mathrm{~mm}$, respectively. Comparatively, for the creep specimens, the mean values were obtained as $494.86 \mathrm{~mm}, 537.05 \mathrm{~mm}$ and $836.05 \mathrm{~mm}$, respectively.

361 Although the value of $L_{\mathrm{ch}}$ was significantly affected by the specimen size, the effects of low 362 sustained loading on $L_{\mathrm{ch}}$ can be reasonably ignored. Accordingly, under higher sustained loading, the brittleness of concrete has been found to increase by Omar et al. [26] if the size effect law is 364 introduced [33].

\section{Conclusions}

366 The concrete specimens with three sizes were prepared to investigate the size effect on the fracture properties of concrete after sustained loading. The creep tests were conducted on the TPB specimens by applying a sustained load of $30 \% P_{\max }$ over 115 days. Thereafter, the standard TPB tests were conducted to measure the initial cracking load, the peak load, the critical crack propagation length and the fracture energy, and the FPZ evolution during the fracture process was determined from the experimental results. By comparing the results of the concrete specimens under static loading with those after sustained loading, the following conclusions can be drawn:

(a) Low sustained loading had a significant effect on the crack initiation, resulting in the increase of the initial cracking load and initial fracture toughness. Also, with the increased specimen size, the initial fracture toughness increased, showing significant variations compared with the results under static loading. However, it should be noted that the derivation of the initial fracture toughness was still based on the LEFM theory and the stress re-distributions were not considered 
in the analyses.

(b) Comparing the experimental and analytical results indicates that the peak load, the critical crack length and the unstable fracture toughness were not affected by the applied sustained loading, while the unstable fracture toughness was still size-independent. Therefore, the calculated method based on the double- $K$ theory is still appropriate for determining the fracture parameters of concrete at the critical fracture status under low sustained loading.

(c) Under the applied low sustained loading, the fracture energy appeared to be size dependent, which is similar to the case under static loading. Meanwhile, the FPZ evolution was affected by the boundary of the specimen and its full length increased with the increasing specimen size, due to the size effect on the fracture energy. In general, the crack initiation was significantly affected by low sustained loading, while this effect can be neglected for the complete crack propagation and the unstable fracture analysis because of no crack propagation at this stage.

\section{Acknowledgements}

The authors gratefully acknowledge the financial support of the National Natural Science Foundation of China under the grants NSFC 51878117, NSFC 51421064 and NSFC 51708565, the Fundamental Research Funds for the Central Universities of China under the grant DUT17LK06, and the National Basic Research Program of China (The 973 Program) under the grant 2015CB057703.

\section{References}

1. Saliba J, Loukili A, Grondin F, Regoin JP (2014) Identification of damage mechanisms in concrete under high level creep by the acoustic emission technique. Mater Struct 47 (6):1041-1053.

2. Van Zijl GPAG, De Borst R and Rots JG (2001) The role of crack rate dependence in the long-term behaviour of cementitious materials. Int J Solids Struct 38 (30-31):5063-5079. 
3. Zhou FP (1992) Time-dependent crack growth and fracture in concrete. Dissertation, Lund University, Sweden.

4. Beushausen H, Masuku C, Moyo P (2012) Relaxation characteristics of cement mortar subjected to tensile strain. Mater Struct 45 (8):1181-1188.

5. Hamed E (2016) Relaxation behavior of concrete under sustained uniaxial compressive deformation. J Mater Civil Eng 28 (6): 06016007(06016001-06016007)

6. Barpi F, Valente S (2011) Failure lifetime of concrete structures under creep and fracture. Mag Concr Res 63 (5):371-376.

7. Bažant ZP, Xian YY (1997) Crack growth and lifetime of concrete under long time loading. J Eng Mech - ASCE 123 (4):350-358.

8. Xu S, Reinhardt HW (1999) Determination of double-K criterion for crack propagation in quasi-brittle fracture: Part I Experimental investigation of crack propagation. Int J Fract 98 (2):111-149.

9. $\mathrm{Xu} \mathrm{S}$, Reinhardt HW (1999) Determination of double-K criterion for crack propagation in quasi-brittle fracture: Part II Analytical evaluating and practical measuring methods for three-point bending notched beams. Int J Fract 98 (2):151-177.

10. Bruhwiler E, Wittmann FH (1990) The wedge splitting test, a new method of performing stable fracture-mechanics tests. Eng Fract Mech 35 (1-3):117-125.

11. Qing L, Dong M, Guan J (2018) Determining initial fracture toughness of concrete for split-tension specimens based on the extreme theory. Eng Fract Mech 189:427-438.

12. Dong W, Wu Z, Zhou X (2013) Calculating crack extension resistance of concrete based on a new crack propagation criterion. Constr Build Mater 38 (1):879-889.

13. Wu Z, Wu X, Dong W, Zheng J, Wu Y (2014) An analytical method for determining the crack extension resistance curve of concrete. Mag Concr Res 66 (14):719-728.

14. Dong W, Wu Z, Tang X, Zhou X (2018) A comparative study on stress intensity factor-based criteria for the prediction of mixed mode I-II crack propagation in concrete. Eng Fract Mech 197:217-235.

15. Hu S, Zhang $\mathrm{X}, \mathrm{Xu} \mathrm{S}$ (2015) Effects of loading rates on concrete double-K fracture parameters. Eng Fract Mech 149:58-73.

16. Wittmann FH, Mihashi H, Nomura N (1990) Size effect on fracture energy of concrete. Eng Fract Mech 35 (1-3):107-115.

17. Zhao Z, Kwon SH, Shah SP (2008) Effect of specimen size on fracture energy and softening curve of concrete: Part I Experiments and fracture energy. Cem Concr Res 38 (8-9):1049-1060.

18. Guan JF, Li QB, Wu ZM, Zhao SB, Dong W, Zhou SW (2016) Fracture parameters of site-cast dam and sieved concrete. Mag Concr Res 68 (1):43-54.

19. Hoover CG, Bažant ZP (2014) Comparison of the Hu-Duan boundary effect model with the size-shape effect law for quasi-brittle fracture based on new comprehensive fracture tests. J Eng Mech 140 (3):480-486.

20. Hu XZ, Guan JF, Wang YS, Keating A, Yang ST (2017) Comparison of boundary and size effect models based on new developments. Eng Fract Mech 175:146-167.

21. Hillerborg A, Modéer M, Petersson PE (1976) Analysis of crack formation and crack growth in concrete by means of fracture mechanics and finite elements. Cem Concr Res 6 (6):773-781. 
22. Wu Z, Rong H, Zheng J, Xu F, Dong W (2011) An experimental investigation on the FPZ properties in concrete using digital image correlation technique. Eng Fract Mech 78 (17):2978-2990.

23. Dong W, Zhou X, Wu Z (2013) On fracture process zone and crack extension resistance of concrete based on initial fracture toughness. Constr Build Mater 49 (12):352-363.

24. Kwon SH, Zhao Z, Shah SP (2008) Effect of specimen size on fracture energy and softening curve of concrete: Part II Inverse analysis and softening curve. Cem Concr Res 38 (8-9):1061-1069.

25. Murthy AR, Karihaloo BL, Iyer NR, Prasad BKR (2013) Bilinear tension softening diagrams of concrete mixes corresponding to their size-independent specific fracture energy. Constr Build Mater 47:1160-1166.

26. Omar M, Loukili A, Pijaudier-Cabot G, Pape YL (2009) Creep-damage coupled effects: Experimental investigation on bending beams with various sizes. J Mater Civil Eng 21 (2):65-72.

27. Carpinteri A, Valente S, Zhou F, Ferrara G, Melchiorri G (1997) Tensile and flexural creep rupture tests on partially-damaged concrete specimens. Mater Struct 30 (5):269-276.

28. Saliba J, Grondin F, Loukili A, Regoin J Coupling creep and damage in concrete under high sustained loading. In: Proceedings of the 7th International Conference in Fracture Mechanics of Concrete and Concrete Structures, Jeju, Korea, 2010.

29. Saliba J, Loukili A, Grondin F, Regoin J (2012) Experimental study of creep-damage coupling in concrete by acoustic emission technique. Mater Struct 45 (9):1389-1401.

30. Bažant ZP, Baweja S, RILEM Committee TC 107-1, ACI Committee 209-2 (1995) Creep and shrinkage prediction model for analysis and design of concrete structures - Model B3. Mater Struct 28 (180):357-365.

31. RILEM TCS 50 (1985) Rilem TC 50-FMC recommendation: Determination of the fracture energy of mortar and concrete by means of three-point bend tests on notched beams. Mater Struct 18 (4):287-290.

32. Petersson PE (1981) Crack growth and development of fracture zones in plain concrete and similar materials. Report TVBM-1006, Division of Building Materials, Lund Institute of Technology, Sweden, 1981.

33. Bažant ZP (1984) Size effect in blunt fracture: concrete, rock, metal. J Eng Mech 110 (4):518-535. 